Supporting Information File

\title{
Tracking the Antibody Immunome in Type 1 Diabetes Using Protein Arrays
}

${ }^{1}$ Xiaofang Bian, ${ }^{2}$ Clive Wasserfall, ${ }^{1}$ Garrick Wallstrom, ${ }^{1}$ Jie Wang, ${ }^{1}$ Haoyu Wang, ${ }^{1}$ Kristi Barker, ${ }^{3}$ Desmond Schatz, ${ }^{2}$ Mark Atkinson, ${ }^{1} \mathrm{Ji}$ Qiu*, ${ }^{1} \mathrm{~J}$ oshua LaBaer*

${ }^{1}$ The Virginia G. Piper Center for Personalized Diagnostics, Biodesign Institute, Arizona State University, Tempe, AZ 85287, USA

${ }^{2}$ Department of Pathology, Immunology and Laboratory Medicine, College of Medicine, University of Florida, Gainesville, FL 32603, USA

${ }^{3}$ Department of Pediatrics, College of Medicine, University of Florida, Gainesville, FL 30607, USA

*Correspondence Authors: Joshua LaBaer, M.D., Ph.D, Virginia G. Piper Chair of Personalized Diagnostics, The Biodesign Institute at Arizona State University, 1001 S. McAllister Ave. PO Box 876401, Tempe, AZ 85287-6401; Email: Joshua.LaBaer@asu.edu; Phone: (480) 965-2805; FAX: (480) 965-3051;

Ji Qiu, Ph.D, Associate Research Professor, The Biodesign Institute at Arizona State University, 1001 S. McAllister Ave. PO Box 876401, Tempe, AZ 85287-6401; Email: Ji.Qiu@asu.edu; Phone: (480) 727-7483 
Supporting Information File

\section{Table of Contents}

Figure S-1. Quality of DNA staining, protein display and serum profiling on NAPPA: (A) Representative slide images of DNA staining, protein display and serum profiling. DNA staining is pesudo-colored in green, protein display and serum profiling is pseudo-colored in rainbow color (Blue, yellow and red indicates low, medium and high signal intensity); (B) Scatter plot of signal intensities of two protein display slides on the left and two serum profiling slides on the right.

Figure S-2. Ring counts of sero-positivity between 40 T1D cases and 40 healthy controls: (A) Number of ring counts of sero-positivity between case and control groups; (B) Venn diagram of ring counts of antigens showed sero-reactivity in as least one case or one control; (C) Venn diagram of ring counts of antigens showed sero-reactivity in as least two cases or two controls; (D) Number of ring counts of sero-positivity between cases $\leq 12$ and $>12$ years.

Figure S-3. Reactivity to IA-2 and GAD65 measured by a commercial assay and RAPID ELISA in sample set 3: (A) Jitter plots of reactivity to IA-2 and GAD65 by commercial assay and RAPOID ELISA; (B) Venn diagram shows the overlap of individuals with reactivity to IA-2 or GAD65 in commercial assay and RAPID ELISA. T1DM: recent-onset T1D patients; HC: healthy controls.

Figure S-4. Comparison of RAPID ELISA with NAPPA and LIPS assay: (A) Bar plots of seroreactivity to IA-2 measured by RAPID ELISA and NAPPA in sample set 1; (B) Bar plots of sero-reactivity to NUP50 measured by RAPID ELISA and LIPS Assay in sample set 2. Red represents patient samples. Green represents control samples.

Figure S-5. Jitter plots of reported AAb biomarkers: (A) DYRK2; (B) UBE2L3 and EEF1A1. T1DM: recent-onset T1D patients; HC: healthy controls. 
Supporting Information File

Figure S-6. ROC analysis of AAb panel: (A) AAb complements to IA-2A; (B) AAb complements to GADA.

Table S-1. The detailed characteristics of each sample set. NA: sample depleted. BD means below detection.

Table S-2. Genes enriched in pancreas. PMID: Pubmed ID.

Table S-3. Characteristic of AAb targets (from Uniprot). 
Figure S-1. Quality of DNA staining, protein display and serum profiling on NAPPA: (A)

Representative slide images of DNA staining, protein display and serum profiling. DNA staining is pesudo-colored in green, protein display and serum profiling is pseudo-colored in rainbow color (Blue, yellow and red indicates low, medium and high signal intensity); (B) Scatter plot of signal intensities of two protein display slides on the left and two serum profiling slides on the right.

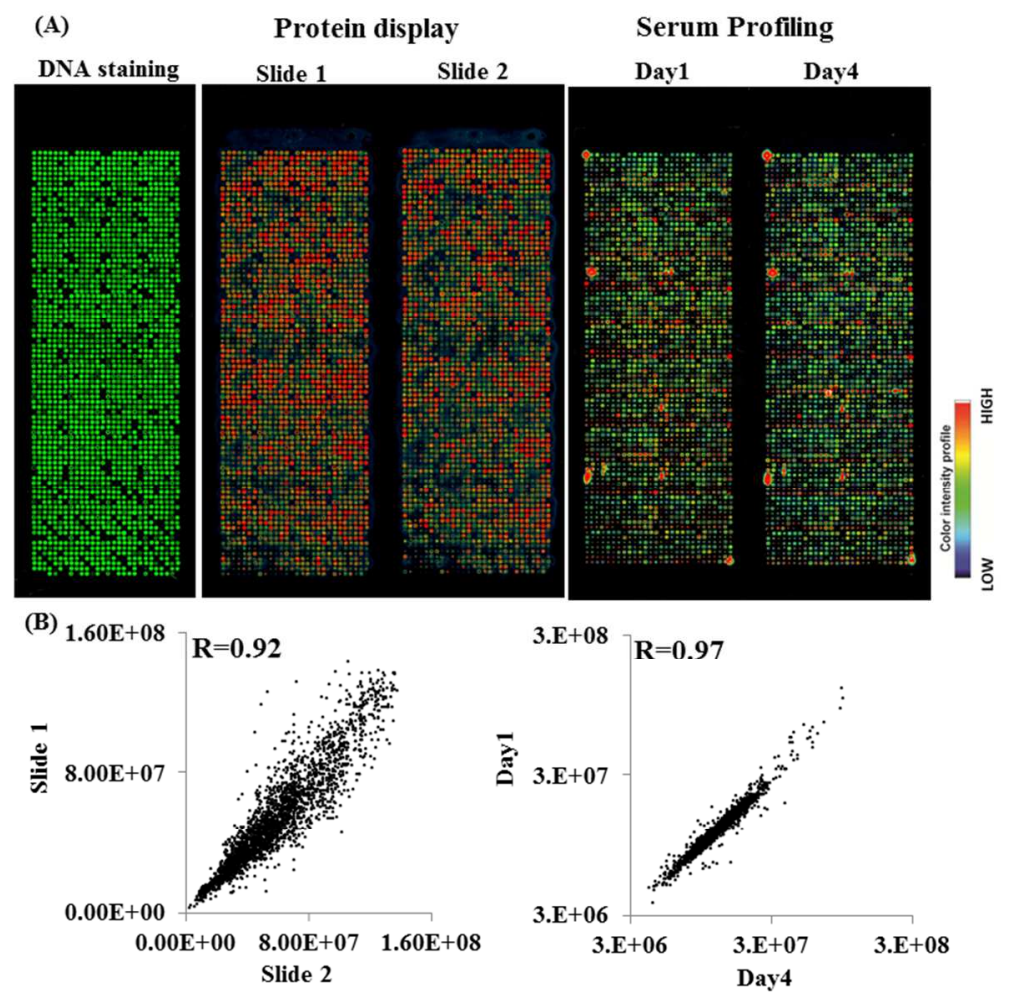


Figure S-2. Ring counts of sero-positivity between 40 T1D cases and 40 healthy controls: (A) Number of ring counts of sero-positivity between case and control groups; (B) Venn diagram of ring counts of antigens showed sero-reactivity in as least one case or one control; (C) Venn diagram of ring counts of antigens showed sero-reactivity in as least two cases or two controls; (D) Number of ring counts of sero-positivity between cases $\leq 12$ and $>12$ years.

(A)

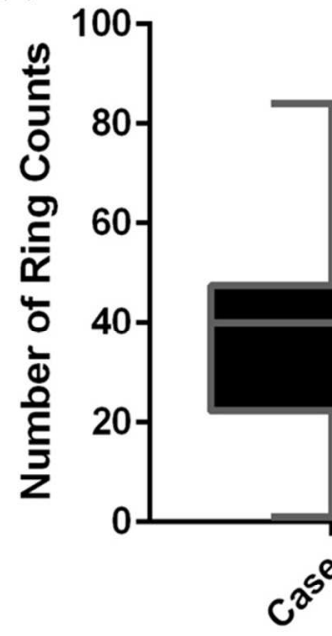

(D)

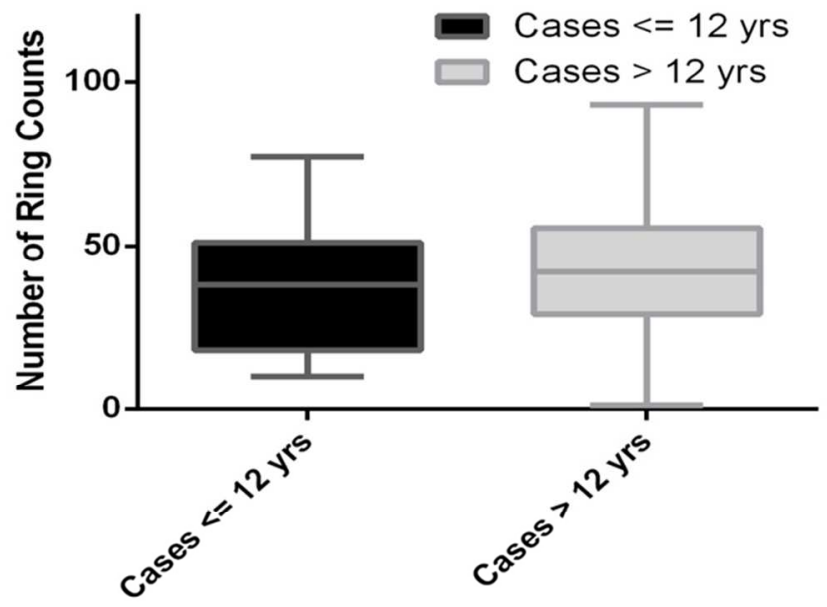

(B) Case $>=1$ Control $>=1$

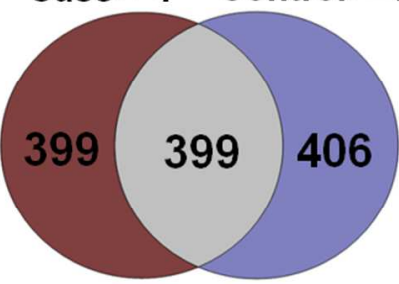

(C)
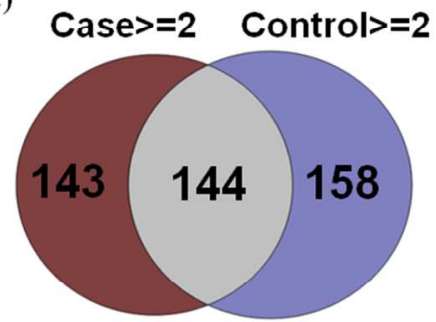
Figure S-3. Reactivity to IA-2 and GAD65 measured by a commercial assay and RAPID ELISA in sample set 3: (A) Jitter plots of reactivity to IA-2 and GAD65 by commercial assay and RAPOID ELISA; (B) Venn diagram shows the overlap of individuals with reactivity to IA-2 or GAD65 in commercial assay and RAPID ELISA. T1DM: recent-onset T1D patients; HC: healthy controls.

(A)
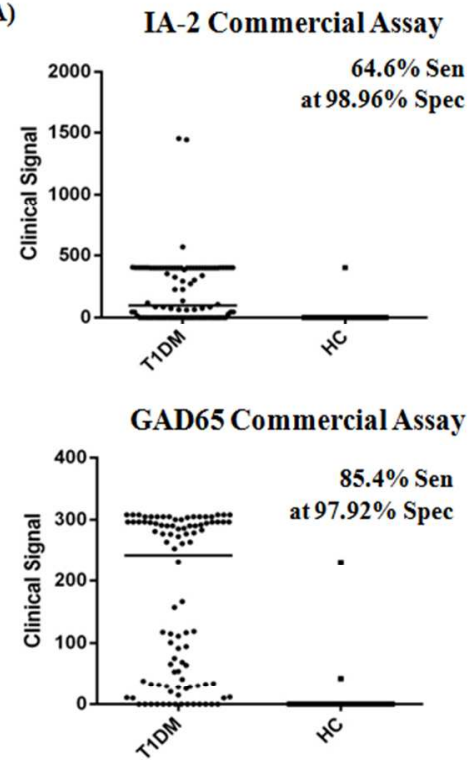

IA-2 RAPID ELISA (B)

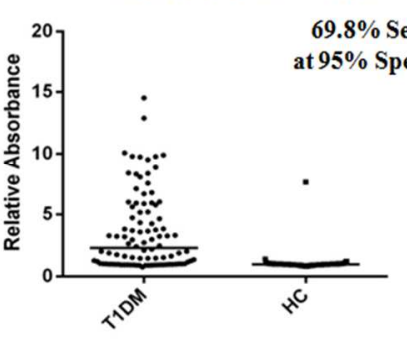

GAD65 RAPID ELISA

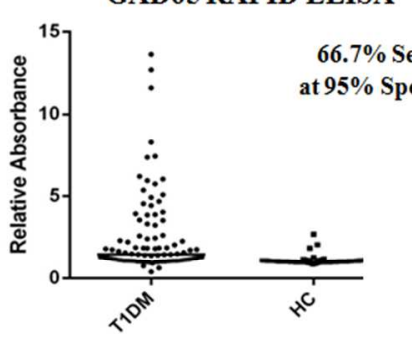

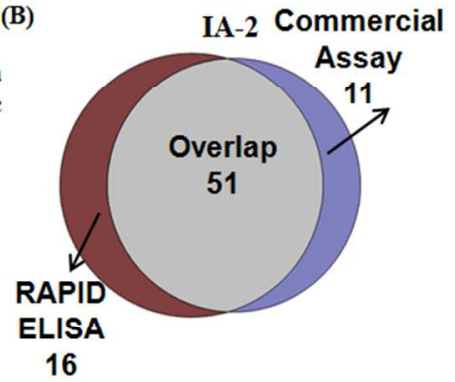

16

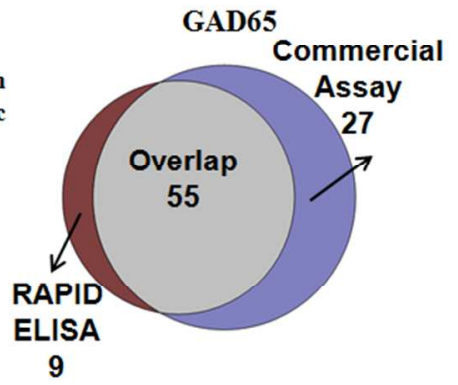


Figure S-4. Comparison of RAPID ELISA with NAPPA and LIPS assay: (A) Bar plots of seroreactivity to IA-2 measured by RAPID ELISA and NAPPA in sample set 1; (B) Bar plots of sero-reactivity to NUP50 measured by RAPID ELISA and LIPS Assay in sample set 2. Red represents patient samples. Green represents control samples.

(A)
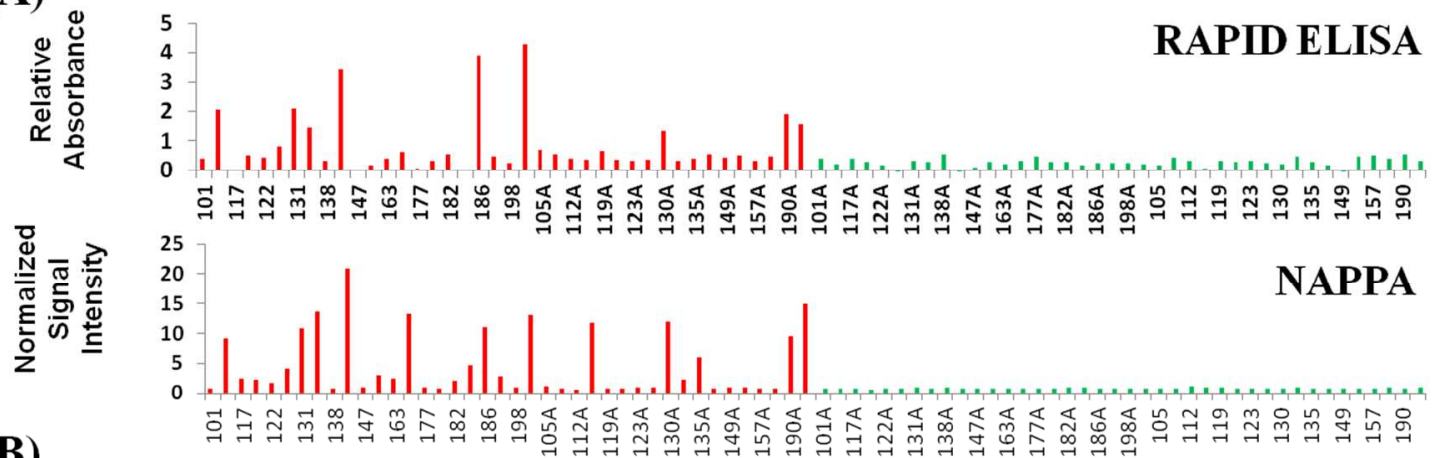

(B)

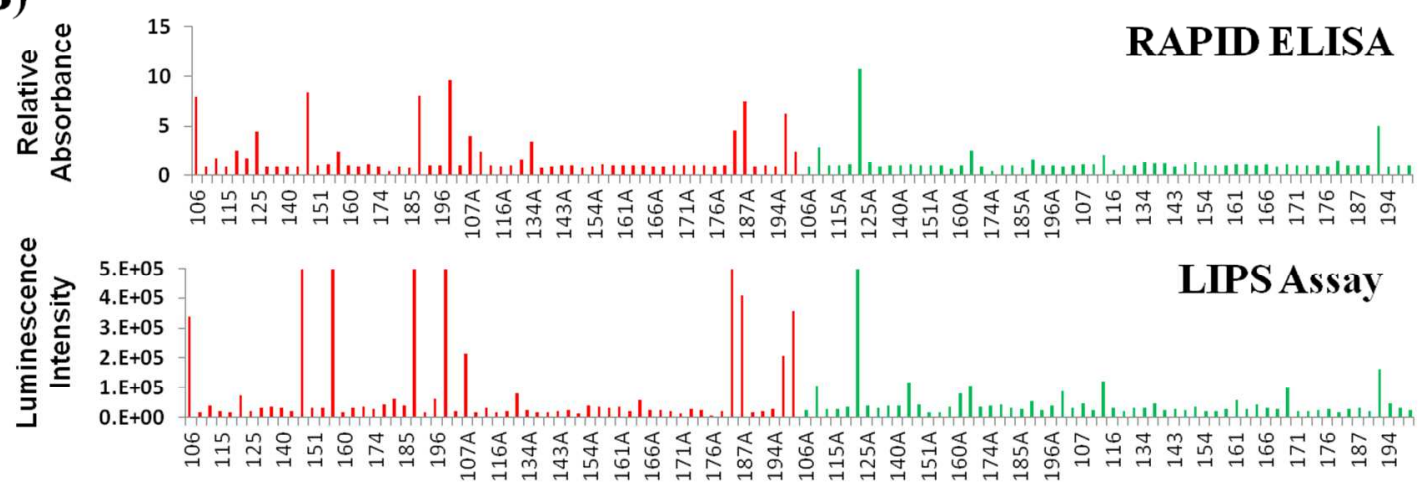


Figure S-5. Jitter plots of reported AAb biomarkers: (A) DYRK2; (B) UBE2L3 and EEF1A1. T1DM: recent-onset T1D patients; HC: healthy controls.

(A)

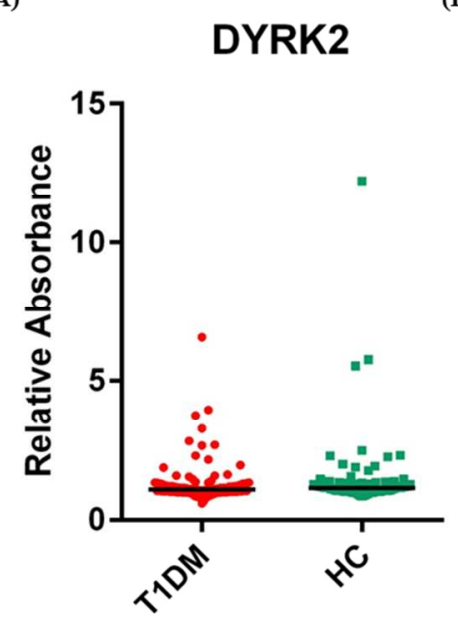

(B)

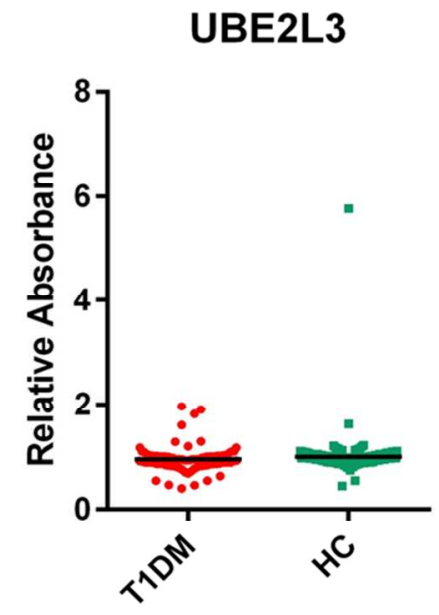

EEF1A1

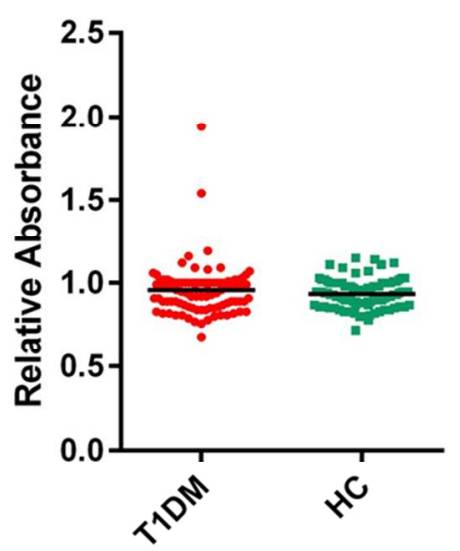


Supporting Information File

Figure S-6. ROC analysis of AAb panel: (A) AAb complements to IA-2A; (B) AAb complements to GADA.

(A)

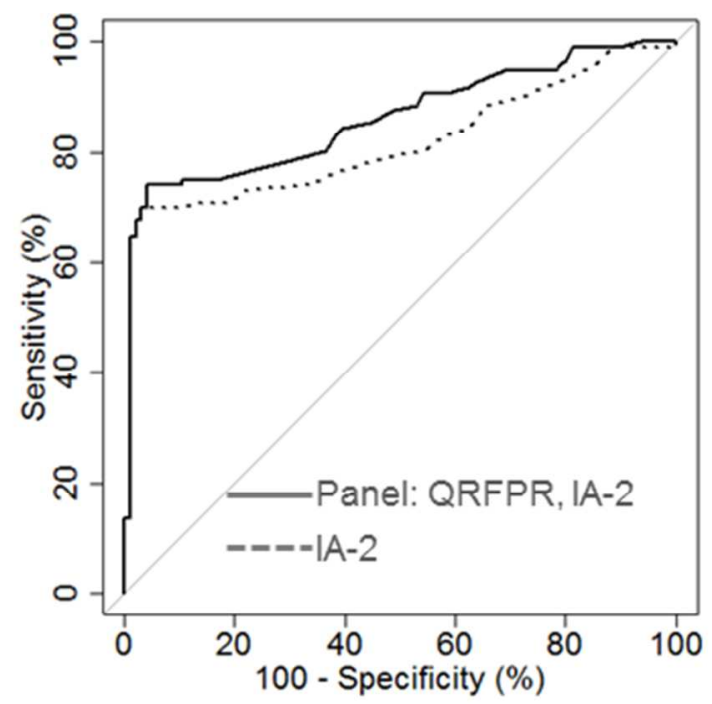

(B)

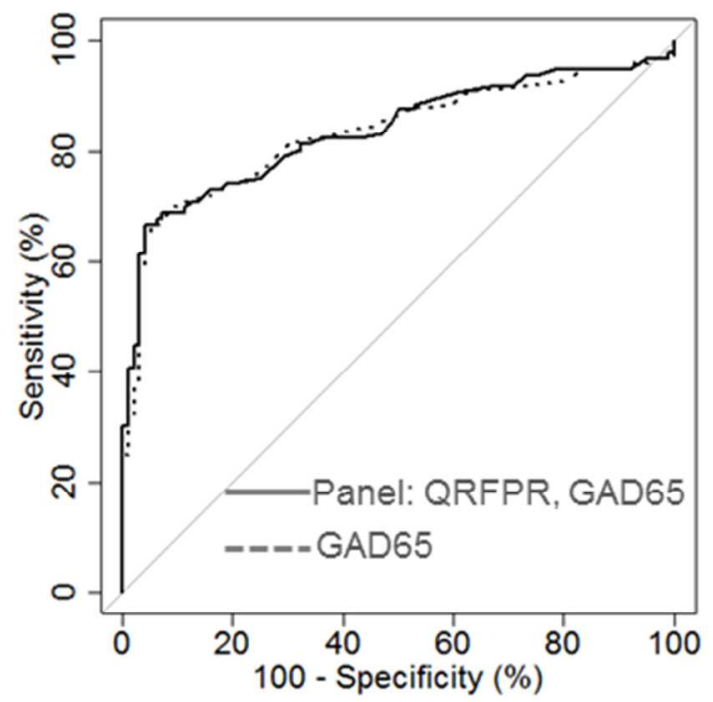


Supporting Information File

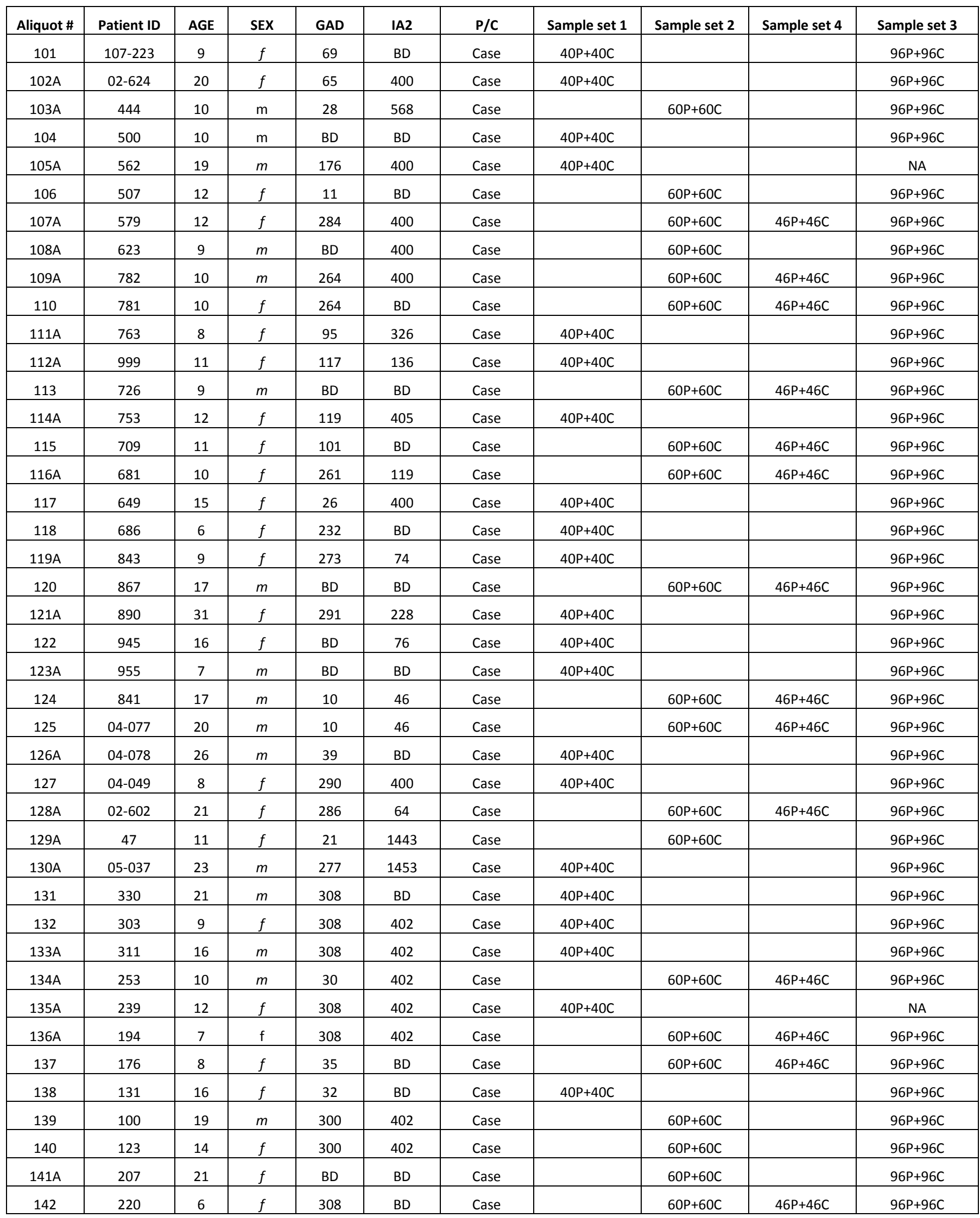


Supporting Information File

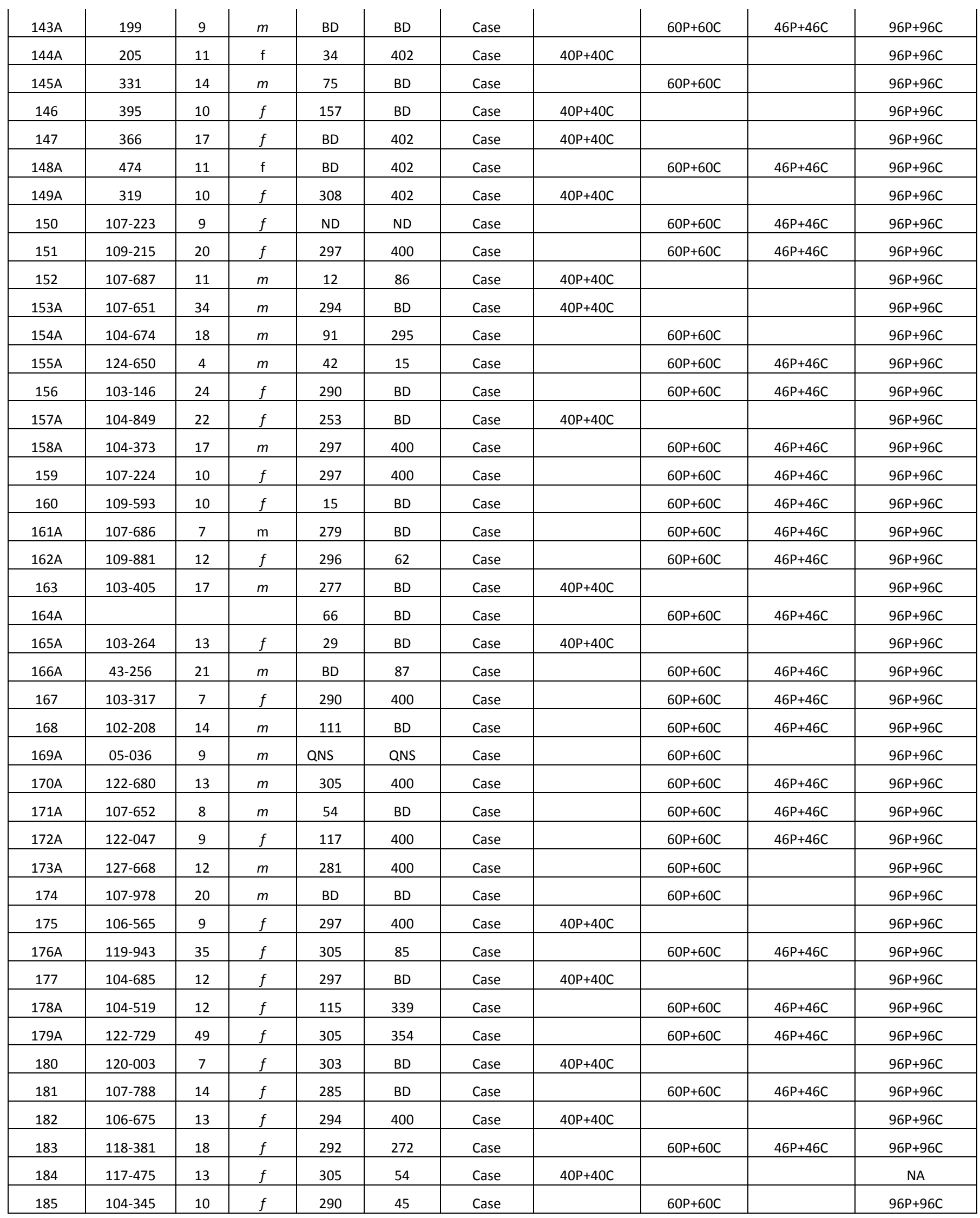


Supporting Information File

\begin{tabular}{|c|c|c|c|c|c|c|c|c|c|c|}
\hline 186 & $106-585$ & 17 & $m$ & 297 & 400 & Case & $40 P+40 C$ & & & $96 P+96 C$ \\
\hline $188 \mathrm{~A}$ & $117-783$ & 31 & $m$ & 305 & 400 & Case & & $60 \mathrm{P}+60 \mathrm{C}$ & $46 P+46 C$ & $96 P+96 C$ \\
\hline 189 & $116-292$ & 19 & $m$ & 305 & 66 & Case & $40 P+40 C$ & & & $96 P+96 C$ \\
\hline $190 \mathrm{~A}$ & 44-643 & 22 & $f$ & 296 & 400 & Case & $40 P+40 C$ & & & NA \\
\hline $191 \mathrm{~A}$ & $116-732$ & 12 & $m$ & 305 & 400 & Case & $40 P+40 C$ & & & $96 P+96 C$ \\
\hline $193 \mathrm{~A}$ & $108-013$ & 26 & $m$ & 277 & 400 & Case & & $60 P+60 C$ & $46 P+46 C$ & $96 \mathrm{P}+96 \mathrm{C}$ \\
\hline $194 \mathrm{~A}$ & $44-611$ & 9 & $m$ & 167 & 302 & Case & & $60 P+60 C$ & $46 \mathrm{P}+46 \mathrm{C}$ & $96 P+96 C$ \\
\hline 195 & $107-701$ & 14 & $m$ & 297 & 400 & Case & & $60 P+60 C$ & $46 P+46 C$ & $96 P+96 C$ \\
\hline 196 & $43-686$ & 10 & $f$ & 296 & 228 & Case & & $60 P+60 C$ & $46 P+46 C$ & $96 P+96 C$ \\
\hline $200 \mathrm{~A}$ & $116-683$ & 9 & $f$ & 305 & 400 & Case & & $60 P+60 C$ & $46 P+46 C$ & $96 P+96 C$ \\
\hline $101 \mathrm{~A}$ & 110747 & 9 & $f$ & $\mathrm{BD}$ & $\mathrm{BD}$ & Control & $40 P+40 C$ & & & $96 P+96 C$ \\
\hline 102 & 743 & 20 & $f$ & $\mathrm{BD}$ & $\mathrm{BD}$ & Control & $40 P+40 C$ & & & $96 P+96 C$ \\
\hline 103 & 110361 & 11 & $\mathrm{~m}$ & $\mathrm{BD}$ & $\mathrm{BD}$ & Control & & $60 P+60 C$ & & $96 P+96 C$ \\
\hline $104 \mathrm{~A}$ & 110673 & 11 & $\mathrm{~m}$ & $\mathrm{BD}$ & $\mathrm{BD}$ & Control & $40 P+40 C$ & & & $96 \mathrm{P}+96 \mathrm{C}$ \\
\hline 105 & 116263 & 19 & $m$ & $\mathrm{BD}$ & $\mathrm{BD}$ & Control & $40 P+40 C$ & & & NA \\
\hline $106 \mathrm{~A}$ & $02-610$ & 12 & $f$ & $\mathrm{BD}$ & $\mathrm{BD}$ & Control & & $60 P+60 C$ & & $96 P+96 C$ \\
\hline 107 & 110267 & 13 & $f$ & $\mathrm{BD}$ & $\mathrm{BD}$ & Control & & $60 P+60 C$ & $46 \mathrm{P}+46 \mathrm{C}$ & $96 P+96 C$ \\
\hline 114 & 88651 & 12 & $f$ & $\mathrm{BD}$ & $\mathrm{BD}$ & Control & $40 P+40 C$ & & & $96 P+96 C$ \\
\hline $115 \mathrm{~A}$ & $110-568$ & 11 & $f$ & $\mathrm{BD}$ & $\mathrm{BD}$ & Control & & $60 \mathrm{P}+60 \mathrm{C}$ & $46 \mathrm{P}+46 \mathrm{C}$ & $96 \mathrm{P}+96 \mathrm{C}$ \\
\hline 116 & $110-728$ & 10 & $f$ & $\mathrm{BD}$ & $\mathrm{BD}$ & Control & & $60 P+60 C$ & $46 \mathrm{P}+46 \mathrm{C}$ & $96 P+96 C$ \\
\hline $117 \mathrm{~A}$ & $112-793$ & 15 & $f$ & $\mathrm{BD}$ & $\mathrm{BD}$ & Control & $40 P+40 C$ & & & $96 \mathrm{P}+96 \mathrm{C}$ \\
\hline $118 \mathrm{~A}$ & 112025 & 6 & $f$ & $\mathrm{BD}$ & $\mathrm{BD}$ & Control & $40 P+40 C$ & & & $96 \mathrm{P}+96 \mathrm{C}$ \\
\hline 119 & 88011 & 9 & $f$ & $\mathrm{BD}$ & $\mathrm{BD}$ & Control & $40 P+40 C$ & & & $96 P+96 C$ \\
\hline $120 \mathrm{~A}$ & 168 & 17 & $m$ & $\mathrm{BD}$ & $\mathrm{BD}$ & Control & & $60 P+60 C$ & $46 \mathrm{P}+46 \mathrm{C}$ & $96 P+96 C$ \\
\hline 121 & 730 & 31 & $f$ & $\mathrm{BD}$ & $\mathrm{BD}$ & Control & $40 \mathrm{P}+40 \mathrm{C}$ & & & $96 P+96 C$ \\
\hline $122 \mathrm{~A}$ & 44-639 & 16 & $f$ & $\mathrm{BD}$ & $\mathrm{BD}$ & Control & $40 P+40 C$ & & & $96 \mathrm{P}+96 \mathrm{C}$ \\
\hline 123 & $110-264$ & 7 & $m$ & $\mathrm{BD}$ & $\mathrm{BD}$ & Control & $40 P+40 C$ & & & $96 P+96 C$ \\
\hline $124 \mathrm{~A}$ & 04-039 & 17 & $m$ & 43 & $\mathrm{BD}$ & Control & & $60 P+60 C$ & $46 \mathrm{P}+46 \mathrm{C}$ & $96 P+96 C$ \\
\hline $125 \mathrm{~A}$ & 3083 & 20 & $m$ & 231 & 402 & Control & & $60 P+60 C$ & $46 \mathrm{P}+46 \mathrm{C}$ & $96 P+96 C$ \\
\hline 126 & 496 & 25 & $m$ & $\mathrm{BD}$ & $\mathrm{BD}$ & Control & $40 P+40 C$ & & & $96 P+96 C$ \\
\hline $127 \mathrm{~A}$ & 83491 & 8 & $f$ & $\mathrm{BD}$ & $\mathrm{BD}$ & Control & $40 P+40 C$ & & & $96 P+96 C$ \\
\hline 128 & 680 & 21 & $f$ & $\mathrm{BD}$ & $\mathrm{BD}$ & Control & & $60 P+60 C$ & $46 P+46 C$ & $96 \mathrm{P}+96 \mathrm{C}$ \\
\hline
\end{tabular}


Supporting Information File

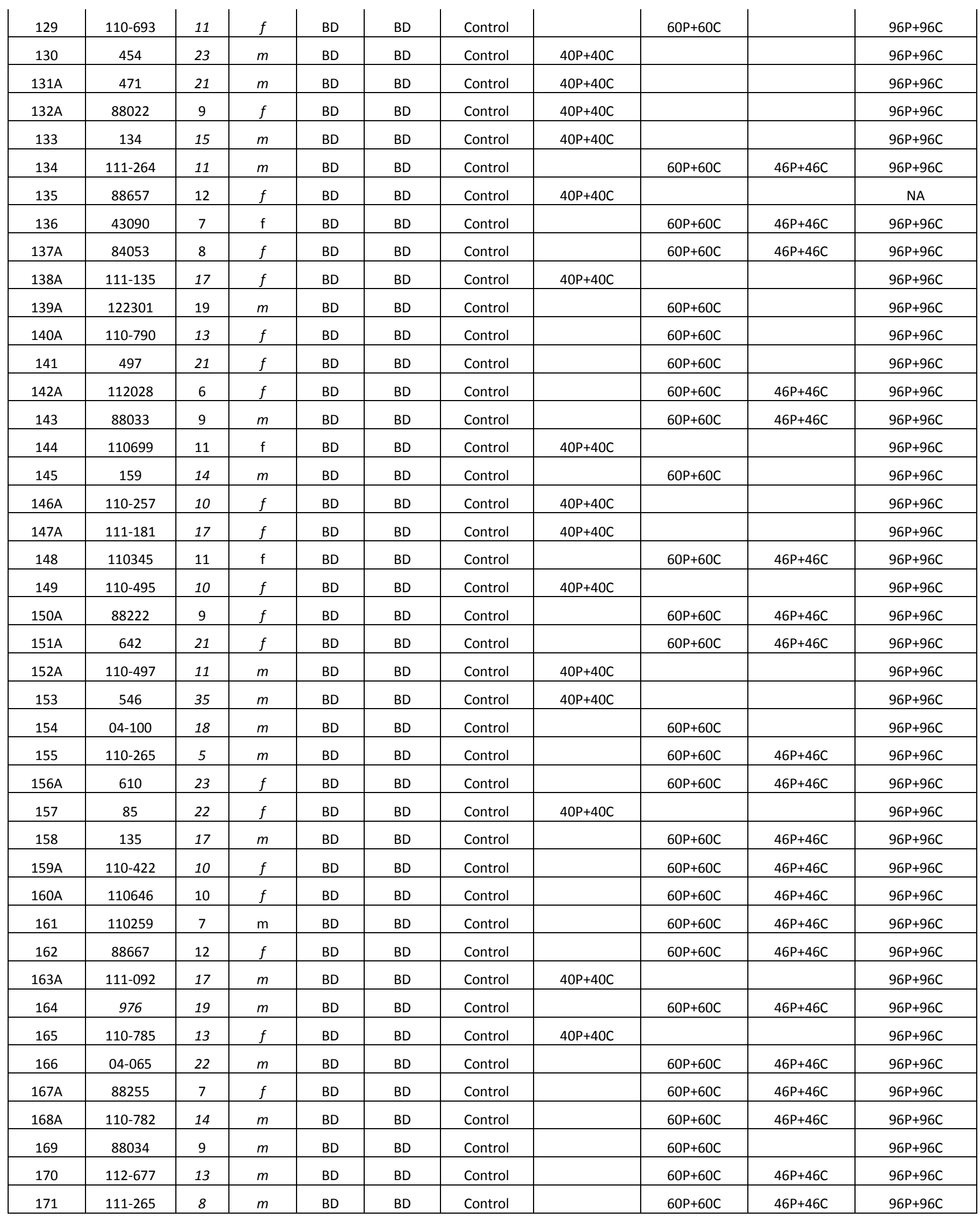


Supporting Information File

\begin{tabular}{|c|c|c|c|c|c|c|c|c|c|c|}
\hline 172 & 88249 & 9 & $f$ & $\mathrm{BD}$ & $\mathrm{BD}$ & Control & & $60 P+60 C$ & $46 \mathrm{P}+46 \mathrm{C}$ & $96 P+96 C$ \\
\hline 173 & $110-781$ & 12 & $m$ & $\mathrm{BD}$ & $B D$ & Control & & $60 P+60 C$ & & $96 P+96 C$ \\
\hline $174 \mathrm{~A}$ & 40728 & 20 & $m$ & $\mathrm{BD}$ & $\mathrm{BD}$ & Control & & $60 P+60 C$ & & $96 P+96 C$ \\
\hline $175 \mathrm{~A}$ & 88253 & 9 & $f$ & $\mathrm{BD}$ & $\mathrm{BD}$ & Control & $40 P+40 C$ & & & $96 P+96 C$ \\
\hline 176 & $110-616$ & 35 & $f$ & $\mathrm{BD}$ & $\mathrm{N} / \mathrm{P}$ & Control & & $60 P+60 C$ & $46 \mathrm{P}+46 \mathrm{C}$ & $96 P+96 C$ \\
\hline $177 \mathrm{~A}$ & 88823 & 12 & $f$ & $\mathrm{BD}$ & $\mathrm{BD}$ & Control & $40 P+40 C$ & & & $96 P+96 C$ \\
\hline 178 & 927 & 13 & $f$ & $\mathrm{BD}$ & $\mathrm{BD}$ & Control & & $60 P+60 C$ & $46 \mathrm{P}+46 \mathrm{C}$ & $96 P+96 C$ \\
\hline 179 & $110-745$ & 48 & $f$ & $\mathrm{BD}$ & $\mathrm{BD}$ & Control & & $60 P+60 C$ & $46 \mathrm{P}+46 \mathrm{C}$ & $96 P+96 C$ \\
\hline $180 \mathrm{~A}$ & 88407 & 7 & $f$ & $\mathrm{BD}$ & $\mathrm{BD}$ & Control & $40 P+40 C$ & & & $96 P+96 C$ \\
\hline $181 \mathrm{~A}$ & $110-786$ & 14 & $f$ & $\mathrm{BD}$ & $\mathrm{BD}$ & Control & & $60 P+60 C$ & $46 \mathrm{P}+46 \mathrm{C}$ & $96 P+96 C$ \\
\hline $182 \mathrm{~A}$ & $110-783$ & 13 & $f$ & $\mathrm{BD}$ & $B D$ & Control & $40 P+40 C$ & & & $96 P+96 C$ \\
\hline $183 \mathrm{~A}$ & 167 & 19 & $f$ & $\mathrm{BD}$ & $\mathrm{BD}$ & Control & & $60 P+60 C$ & $46 \mathrm{P}+46 \mathrm{C}$ & $96 P+96 C$ \\
\hline $184 \mathrm{~A}$ & $110-789$ & 13 & $f$ & $\mathrm{BD}$ & $\mathrm{BD}$ & Control & $40 P+40 C$ & & & NA \\
\hline $185 \mathrm{~A}$ & 88023 & 10 & $f$ & $\mathrm{BD}$ & $\mathrm{BD}$ & Control & & $60 P+60 C$ & & $96 P+96 C$ \\
\hline $186 \mathrm{~A}$ & $111-177$ & 17 & $m$ & $\mathrm{BD}$ & $\mathrm{BD}$ & Control & $40 P+40 C$ & & & $96 P+96 C$ \\
\hline 187 & 88063 & 9 & $m$ & $\mathrm{BD}$ & $\mathrm{BD}$ & Control & & $60 P+60 C$ & $46 P+46 C$ & $96 P+96 C$ \\
\hline 188 & 196 & 29 & $m$ & $\mathrm{BD}$ & $\mathrm{BD}$ & Control & & $60 P+60 C$ & $46 \mathrm{P}+46 \mathrm{C}$ & $96 P+96 C$ \\
\hline $189 \mathrm{~A}$ & 112797 & 19 & $m$ & $\mathrm{BD}$ & $\mathrm{BD}$ & Control & $40 P+40 C$ & & & $96 P+96 C$ \\
\hline 190 & 470 & 23 & $f$ & $\mathrm{BD}$ & $\mathrm{BD}$ & Control & $40 P+40 C$ & & & NA \\
\hline 191 & 126 & 12 & $m$ & $\mathrm{BD}$ & $\mathrm{BD}$ & Control & $40 P+40 C$ & & & $96 P+96 C$ \\
\hline $192 \mathrm{~A}$ & $110-788$ & 13 & $f$ & $\mathrm{BD}$ & $\mathrm{BD}$ & Control & & $60 P+60 C$ & $46 P+46 C$ & $96 P+96 C$ \\
\hline 193 & 149 & 26 & $m$ & $\mathrm{BD}$ & $\mathrm{BD}$ & Control & & $60 P+60 C$ & $46 \mathrm{P}+46 \mathrm{C}$ & $96 P+96 C$ \\
\hline 194 & 88089 & 9 & $m$ & $\mathrm{BD}$ & $\mathrm{BD}$ & Control & & $60 P+60 C$ & $46 \mathrm{P}+46 \mathrm{C}$ & $96 P+96 C$ \\
\hline $195 \mathrm{~A}$ & 04-040 & 15 & $m$ & $\mathrm{BD}$ & $\mathrm{BD}$ & Control & & $60 P+60 C$ & $46 \mathrm{P}+46 \mathrm{C}$ & $96 P+96 C$ \\
\hline $196 \mathrm{~A}$ & 88026 & 10 & $f$ & $\mathrm{BD}$ & $\mathrm{BD}$ & Control & & $60 P+60 C$ & $46 P+46 C$ & $96 P+96 C$ \\
\hline 197 & 40802 & 18 & $m$ & $\mathrm{BD}$ & $\mathrm{BD}$ & Control & & $60 P+60 C$ & $46 \mathrm{P}+46 \mathrm{C}$ & $96 P+96 C$ \\
\hline $198 \mathrm{~A}$ & 43732 & 20 & $m$ & $\mathrm{BD}$ & $\mathrm{BD}$ & Control & $40 P+40 C$ & & & $96 P+96 C$ \\
\hline $199 A$ & 88029 & 10 & $f$ & $\mathrm{BD}$ & $\mathrm{BD}$ & Control & & $60 P+60 C$ & & $96 P+96 C$ \\
\hline 200 & 88834 & 12 & $f$ & $\mathrm{BD}$ & $B D$ & Control & & $60 P+60 C$ & $46 P+46 C$ & $96 \mathrm{P}+96 \mathrm{C}$ \\
\hline
\end{tabular}

Table S-1. The detailed characteristics of each sample set. NA: sample depleted. BD means below detection. 
Supporting Information File

\begin{tabular}{|c|c|c|}
\hline Source & Gene & Overlap \\
\hline Gene expression analysis & ADAMTS18 & \\
\hline Gene expression analysis & AMY2A & \\
\hline Gene expression analysis & AMY2B & \\
\hline Gene expression analysis & ANXA4 & \\
\hline Gene expression analysis & AQP12B & \\
\hline Gene expression analysis & AQP8 & \\
\hline Gene expression analysis & C21orf2 & \\
\hline Gene expression analysis & CLPS & \\
\hline Gene expression analysis & CPA1 & \\
\hline Gene expression analysis & CPA2 & \\
\hline Gene expression analysis & CPB1 & \\
\hline Gene expression analysis & CSMD2 & \\
\hline Gene expression analysis & CTRB1 & \\
\hline Gene expression analysis & CTRC & \\
\hline Gene expression analysis & CTRL & \\
\hline Gene expression analysis & ELA2A & \\
\hline Gene expression analysis & ELA2B & \\
\hline Gene expression analysis & ELA3A & \\
\hline Gene expression analysis & ERP27 & \\
\hline Gene expression analysis & IL22RA1 & \\
\hline Gene expression analysis & KLK1 & \\
\hline Gene expression analysis & NIP7 & \\
\hline Gene expression analysis & NR5A2 & \\
\hline Gene expression analysis & PFKL & \\
\hline Gene expression analysis & PLA2G1B & \\
\hline Gene expression analysis & PNLIP & \\
\hline Gene expression analysis & PNLIPRP1 & \\
\hline Gene expression analysis & PNLIPRP2 & \\
\hline Gene expression analysis & PRSS1 & \\
\hline Gene expression analysis & PRSS3 & \\
\hline Gene expression analysis & GCG & Overlap with genes from other sources \\
\hline Gene expression analysis & REG3A & Overlap with genes from other sources \\
\hline Gene expression analysis & IAPP & Overlap with genes from other sources \\
\hline Gene expression analysis & RBPJL & \\
\hline Gene expression analysis & RCBTB2 & \\
\hline Gene expression analysis & PPY & Overlap with genes from other sources \\
\hline Gene expression analysis & REG1A & \\
\hline Gene expression analysis & REG1B & \\
\hline Gene expression analysis & SERPINI2 & \\
\hline
\end{tabular}




\section{Supporting Information File}

\begin{tabular}{|c|c|c|}
\hline Gene expression analysis & REG3G & Overlap with genes from other sources \\
\hline Gene expression analysis & SLC43A1 & \\
\hline Gene expression analysis & SNRPN & \\
\hline Gene expression analysis & SPINK1 & \\
\hline Gene expression analysis & SYCN & \\
\hline Gene expression analysis & TGOLN2 & \\
\hline Gene expression analysis & TMED6 & \\
\hline PMID:17942684 & IAPP & Overlap with genes from other sources \\
\hline PMID:17942684 & CPE & Overlap with genes from other sources \\
\hline PMID:17942684 & G6PC2/IGRP & Overlap with genes from other sources \\
\hline PMID:17942684 & APLP1 & \\
\hline PMID:17942684 & ATP2A3 & \\
\hline PMID:17942684 & CEACAM1 & \\
\hline PMID:17942684 & CHGA & Overlap with genes from other sources \\
\hline PMID:17942684 & REG3G & Overlap with genes from other sources \\
\hline PMID:17942684 & CLU & Overlap with genes from other sources \\
\hline PMID:17942684 & REG3A & Overlap with genes from other sources \\
\hline PMID:17942684 & ICA1/ICA69 & Overlap with genes from other sources \\
\hline PMID:17942684 & SNAP25 & Overlap with genes from other sources \\
\hline PMID:17942684 & ENO2 & \\
\hline PMID:17942684 & IMO38/MRPS31 & Overlap with genes from other sources \\
\hline PMID:17942684 & ERO1LB & \\
\hline PMID:17942684 & NPY & Overlap with genes from other sources \\
\hline PMID:17942684 & FXYD2 & \\
\hline PMID:17942684 & GJA4 & \\
\hline PMID:17942684 & GLIPR1 & \\
\hline PMID:17942684 & GNAS & \\
\hline PMID:17942684 & HMGN3 & \\
\hline PMID:17942684 & SOX13 & Overlap with genes from other sources \\
\hline PMID:17942684 & HPN & \\
\hline PMID:17942684 & HSP90AB1 & \\
\hline PMID:17942684 & IGF1 & \\
\hline PMID:17942684 & INPP5E & \\
\hline PMID:17942684 & KCNMB2 & \\
\hline PMID:17942684 & KRT17 & \\
\hline PMID:17942684 & LYPD5 & \\
\hline PMID:17942684 & NKX2.2 & \\
\hline PMID:17942684 & PAX6 & \\
\hline PMID:17942684 & PROM1 & \\
\hline PMID:17942684 & PRPH & \\
\hline
\end{tabular}


Supporting Information File

\begin{tabular}{|c|c|c|}
\hline PMID:17942684 & RAMP2 & \\
\hline PMID:17942684 & SCG2 & \\
\hline PMID:17942684 & SCG3 & \\
\hline PMID:17942684 & SCGN & \\
\hline PMID:17942684 & SEZ6L2 & \\
\hline PMID:17942684 & SGNE1/7B2 & \\
\hline PMID:17942684 & sox17 & \\
\hline PMID:17942684 & SYP & \\
\hline PMID:17942684 & SYT13 & \\
\hline PMID:17942684 & SYTL4 & \\
\hline PMID:17942684 & TM4SF4 & \\
\hline PMID:17942684 & TOB1 & \\
\hline PMID: 18359275 & $\mathrm{AMPH}$ & \\
\hline PMID: 18359275 & ARFGAP1 & \\
\hline PMID: 18359275 & FLOT & \\
\hline PMID: 18359275 & FURIN & \\
\hline PMID: 18359275 & GAPDH & \\
\hline PMID: 18359275 & GCK & \\
\hline PMID: 18359275 & GFAP & \\
\hline PMID: 18359275 & HOXB7 & \\
\hline PMID: 18359275 & JUNB & \\
\hline PMID: 18359275 & Rab11 & \\
\hline PMID: 18359275 & Rab3A & \\
\hline PMID: 18359275 & Rab5A & \\
\hline PMID: 18359275 & Rab8B & \\
\hline PMID: 18359275 & RPH3A & \\
\hline PMID: 18359275 & S100B & \\
\hline PMID: 18359275 & SCAMP2 & \\
\hline PMID: 18359275 & SNAP29 & \\
\hline PMID: 18359275 & SNTB2 & \\
\hline PMID: 18359275 & SNX1 & \\
\hline PMID: 18359275 & SNX6 & \\
\hline PMID: 18359275 & CPE & Overlap with genes from other sources \\
\hline PMID: 18359275 & CHGA & Overlap with genes from other sources \\
\hline PMID: 18359275 & STX1A & \\
\hline PMID: 18359275 & STX6 & \\
\hline PMID: 18359275 & STXBP1 & \\
\hline PMID: 18359275 & SV2C & \\
\hline PMID: 18359275 & IMO38/MRPS31 & Overlap with genes from other sources \\
\hline PMID: 18359275 & ICA1/ICA69 & Overlap with genes from other sources \\
\hline
\end{tabular}


Supporting Information File

\begin{tabular}{|c|c|c|}
\hline PMID: 18359275 & SYT1 & \\
\hline PMID: 18359275 & G6PC2/IGRP & Overlap with genes from other sources \\
\hline PMID: 18359275 & NPY & Overlap with genes from other sources \\
\hline PMID: 18359275 & VAMP2 & \\
\hline PMID: 18359275 & SNAP25 & Overlap with genes from other sources \\
\hline PMID: 18359275 & Sox13 & Overlap with genes from other sources \\
\hline PMID: 23500132 & ASB9 & \\
\hline PMID: 23500132 & C4ORF18 & \\
\hline PMID: 23500132 & CCDC116 & \\
\hline PMID: 23500132 & DGCR2 & \\
\hline PMID: 23500132 & ENO3 & \\
\hline PMID: 23500132 & KLHDC3 & \\
\hline PMID: 23500132 & MYOD1 & \\
\hline PMID: 23500132 & QRFPR & \\
\hline PMID: 23500132 & SCG5 & \\
\hline PMID: 23500132 & SerpinB10 & \\
\hline PMID: 23500132 & SV2A & \\
\hline PMID: 23500132 & TMEMЗОА & \\
\hline PMID: 23500132 & CLU & Overlap with genes from other sources \\
\hline PMID: 23500132 & GCG & Overlap with genes from other sources \\
\hline PMID: 23500132 & PPY & Overlap with genes from other sources \\
\hline PMID: 23500132 & SNAP25 & Overlap with genes from other sources \\
\hline
\end{tabular}

Table S-2. Genes enriched in pancreas. PMID: Pubmed ID. 
Supporting Information File

\begin{tabular}{|c|c|c|c|c|c|c|}
\hline Gene & Uniprot & Descrintion & Tissue Snecificity & Subcellular & General Funcion & Relation with Diabetes \\
\hline & & Receptor-type tyrosine-protein & & Cytoplasmic & & \\
\hline PTPRN2 & Q92932 & phosphatase N2 & $\begin{array}{c}\text { Brain and pancreas } \\
\text { ymphocytes, spleen, testis, }\end{array}$ & vesicle & Transmembrane receptor & PMID: 8637868 \\
\hline MLH1 & P40692 & $\begin{array}{l}\text { DNA mismatch repair protein } \\
\text { Translation initiation factor IF-3, }\end{array}$ & $\begin{array}{l}\text { thyroid, et,al. } \\
\text { Highest in thymus, pancreas and }\end{array}$ & Nucleus & DNA repair & PMID: 23025454 \\
\hline MTIF3 & Q9H2KO & $\begin{array}{l}\text { mitochondrial } \\
\text { Peptidyl-prolyl cis-trans isomerase- }\end{array}$ & $\begin{array}{c}\text { testis } \\
\text { Highest in thymus, pancreas and }\end{array}$ & Mitochondrion & Translation initiation & PMID: 24885863 \\
\hline PPIL2 & Q13356 & like 2 & testis & Nucleus & Chaperone, ubiquitin ligase activity & N/A \\
\hline NUP50 & Q9UKX7 & Nuclear pore complex protein Nup50 & Ubiquitous. & Nucleus & Nuclear pore complex component & N/A \\
\hline QRFPR & A1A4W1 & QRFPR protein & Pancreas & Membrane & Neuopeptide $Y$ receptor activity & PMID: 24622796 \\
\hline
\end{tabular}

Table S-3. Characteristic of AAb targets (from Uniprot). 